\title{
The effect of environmental changes on distribution of Pasteurella multocida in marsh buffaloes in south of Iraq. ${ }^{1}$ Ibrahim Abbas Mohammed, ${ }^{2}$ Jalil Abed Gatie
}

Thi-Qar Vet. Hospital, Vet. Directorate .Ministry of agriculture

\begin{abstract}
The study was conducted to investigate the distribution of Pasteurella multocida in marsh buffaloes in south of Iraq and effect of environmental changes on distribution of Pasteurella multocida. A total 393 buffaloes of different ages and sexes, from May/2017 to April/2018, were clinically examined. Enrich and Selective medias ,biochemical test and Gram stain were used. All positive cases confirmed by polymerase chain reaction with specific primer to $P$. multocida. Statistically the distribution of P. multocida in infected buffalos (28\%) were significantly higher than non-infected (14\%).some buffalos with the clinical sings of hemorrhagic septicemia (HS). While other buffaloes showed clinical finding of Bovine respiratory disease (BRD) and other appeared normally. The isolation recorded in male $26 \%$ and in female $25 \%$ The number of infected buffaloes under one year of age $(32.8 \%)$ showed significantly higher than 1-2 year (19.6\%) and adult animal(18.9\%). The distribution rate were $25.3 \%, 24.4 \%, 26.4 \%$ in Basrah. Dhi Qar, Misan respectively but there were no significantly variation between Provinces .Also The lower percentage of isolation in October /2017 (9\%). and highest in February /2018 (37\%), Significant correlations between distribution rates and mean of temperature at $(\mathrm{P} \leq 0.01)$ level but its non-significantly correlations between distribution rates and mean of humidity. We describe the P.multocida endemic in marsh buffaloes in south of Iraq, under 1 year old are more prone to $P$. multocida. There were a significant negative correlations between distribution rates and mean of temperatures
\end{abstract}

Key words; Pasteurella multocida, Buffaloes, environmental changes. Iraq

\section{i. INTRODUCTION}

Pasteurella multocida, a Gram negative pathogen bacteria and it can produce many type of diseases to many species of animals. hemorrhagic septicemia are important economic disease caused by Pasteurella multocida because it fatal to buffaloes in many cases, Pasteurella multocida also causes Bovine Respiratory Diseases in buffaloes but less than hemorrhagic septicemia and it is also etiological agent pneumonia in ovine and caprine also Pasteurella multocida causes fowl cholera in poultry, $\left({ }^{1 ; 2}\right)$. 
Pasteurella multocida is found as a normal flora in respiratory tract but under stress or other infection like para influenza virus infection ,this will lead to enhance Pasteurella multocida infection so Pasteurellosis outbreak mostly occur in raining season $\left({ }^{3,4}\right)$

Clinical finding of hemorrhagic septicemia (HS) which caused by P.multocida appear as an increase of temperature, difficult in respiration ,at same time serious then become mucoid discharge from nasal orifices, mouth frothing, and submandibular edema was observe, then after hours. animal will be recumbence then death in less than 7hours. While the infection with Bovine Respiratory Diseases: mostly include Respiratory disease (rhinitis to pneumonia. ) and may death in some cases and it called Bovine Respiratory Diseases .(BRD). $\left({ }^{5}\right)$.

The young buffalo and calves at age (6 Months to 2 years) most Susceptibility to P.multocida $\left({ }^{2}\right)$

Pasteurella multocida can be isolated from necropsy samples directly after death, like blood, lungs spleen or liver, also can be isolated from bone marrow after days of dead animals. In living animals blood or mucus from the nostrils or swabbing from the nasal cleft can be used for culturing $\left(^{6}\right)$.

In many Asian countries, outbreaks mostly occur during seasons of high humidity and high temperatures $\left({ }^{7,8}\right)$.

In Iraq, Pasteurella multocida causes many outbreaks and infections, thus there were many studies on cattle and buffaloes like $\left({ }^{8}\right)$ in marshes in south of iraq, $\left({ }^{9}\right)$ in Basrah ; and $\left({ }^{3,10,11}\right)$ in Baghdad, our country needed more studies required to investigation Pasteurella multocida distribution and the genotypes that cause the disease in buffaloes

Aims of study :

1. Investigate the presence of P.multocida in buffaloes in marshes in south of Iraq.

2. Effect of environmental changes on distribution of P.multocida

\section{ii. MATERIAL AND METHODS}

Animals of study and sample collection

The survey study to buffaloes in Marshes of south of Iraq in Thi-Qar, Basra and Misan provinces 393 buffaloes were examined clinically from marshes area ,different in age and sex ,between May/2017 to April/2018

Table (1) locations of taken samples from buffaloes in Marshes area according to Provinces

\begin{tabular}{|c|c|c|c|c|c|}
\hline Provinces & & Location & Samples & North line & East line \\
\hline \multirow{4}{*}{$\begin{array}{ll}\text { Basrah } 130 \\
\text { Samples }\end{array}$} & 1 & AlMdina & 34 & 30.979587 & 47.208785 \\
\hline & 2 & Alhower & 24 & 30.966508 & 47.315374 \\
\hline & 3 & Showarea & 37 & 30.724765 & 46.819286 \\
\hline & 4 & Ghabishia\&Nigamshi & 35 & 30.700430 & 46.856965 \\
\hline DhiQar 127 & 5 & Ghibash & 35 & 30.973575 & 47.137087 \\
\hline
\end{tabular}




\begin{tabular}{|l|l|l|l|l|l|}
\hline Samples & 6 & Al Tar & 34 & 30.935454 & 46.747348 \\
\cline { 2 - 6 } & 7 & AlAmni & 20 & 30.776862 & 46.656428 \\
\cline { 2 - 6 } & 8 & Suq Al Shoukh\Um Al Wadea & 38 & 30.836915 & 46.564967 \\
\hline \multirow{3}{*}{$\begin{array}{l}\text { Misan } \\
\text { 136 Samples }\end{array}$} & 9 & AlOmara/Al Misbaneah & 36 & 31.862985 & 47.212388 \\
& 10 & Al Musharah & 32 & 31.854155 & 47.368365 \\
\cline { 2 - 6 } & 11 & Al Salam & 35 & 31.476647 & 46.887415 \\
\hline & 12 & Al Adil & 33 & 31.512855 & 46954867 \\
\hline
\end{tabular}

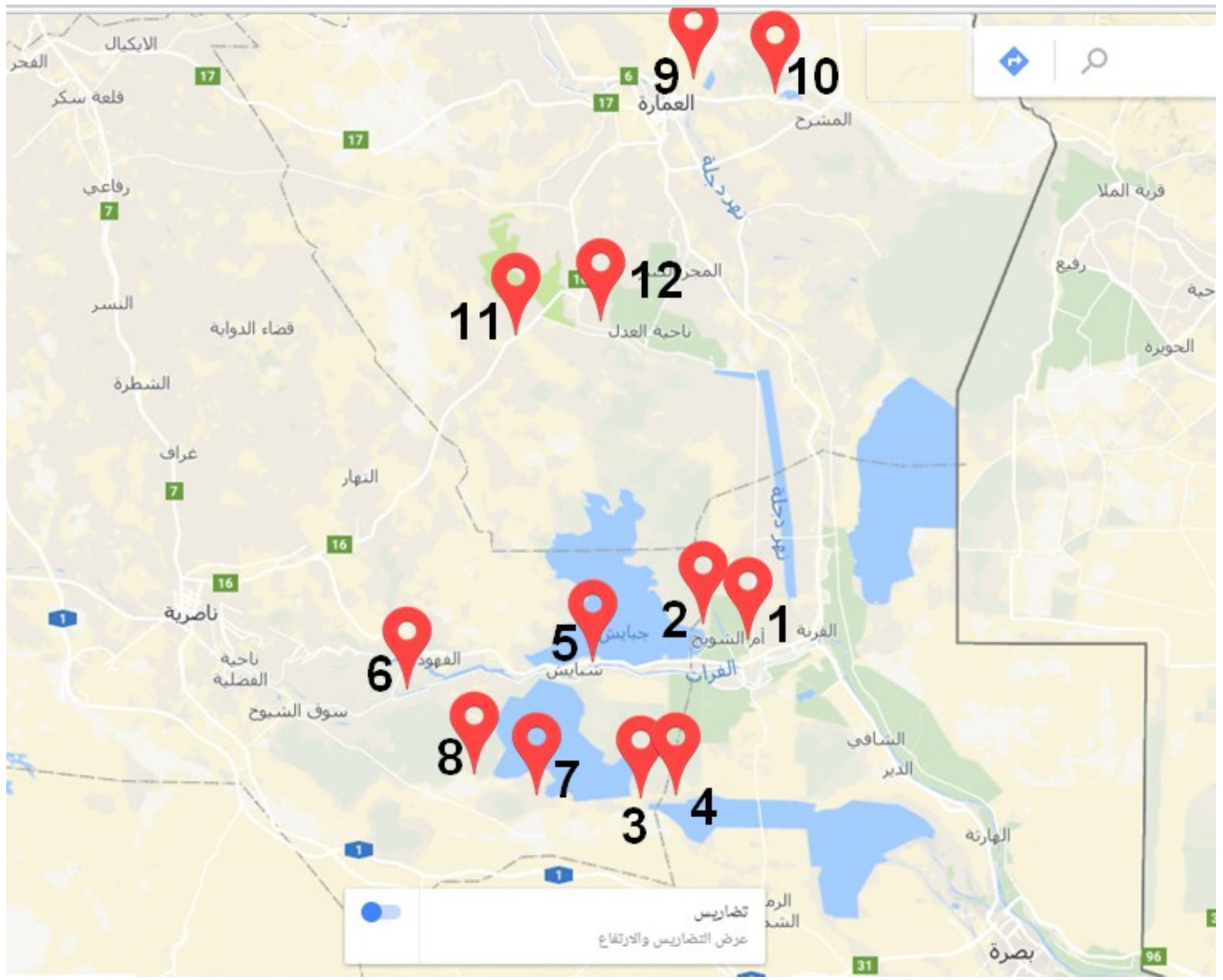

Figure. (1) Showed locations of taken samples from buffaloes in marshes area according to Provinces (Google earth)

Survey study

Nasal swabs were taken from each one

Culture and staining and biochemical 
Identification of P. multocida by following media (Brain heart infusion broth (BHI), Blood Agar, MacConkey Agar ),

Gram stain and biochemical test catalase test ,oxidase , indole, urase ,triple sugar iron,

$\left({ }^{6}\right)$

\section{Conventional PCR study}

Conventional PCR assay was used for detection of Pasteurella multocida by amplificated of universal primers $\left({ }^{12}\right)$

The experiment was carried out in the clinical pathology Laboratory of Internal and Preventive Medicine department in College of Veterinary Medicine-University of Baghdad

Table (2) PCR primer for detection of Pasteurella multocida

\begin{tabular}{|l|l|l|l|}
\hline \multirow{2}{*}{ Primer } & \multicolumn{2}{|l|}{ Sequence } & PCR Amplicon \\
\hline \multirow{2}{*}{ KMT-1 } & $\mathrm{F}$ & GCTGTAAACGAACTCGCCC & \multirow{2}{*}{$460 \mathrm{bp}$} \\
\cline { 2 - 3 } & $\mathrm{R}$ & ATCCGCTATTTACCCAGTGG & \\
\hline
\end{tabular}

Statistical analysis:

Statistical analysis were done by Chi-square test between parameters, and correlation between parameters $\left({ }^{13}\right)$

\section{iii. THE RESULT AND DISCUSSION}

- The of Pasteurella multocida Distribution in Marshes

distribution rate of Pasteurella multocida which was isolated from diseased buffaloes were(34\%)and it was significantly higher at $(\mathrm{P} \leq 0.05)$ than non-Diseased buffaloes $(14 \%)$.

Tab. (3) Distribution rate of Pasteurella multocida in buffaloes according to clinical sings

\begin{tabular}{|l|l|l|l|}
\hline Clinically & Samples & Positive & Distribution rate \% \\
\hline
\end{tabular}




\begin{tabular}{|l|l|l|l|}
\hline Diseased & 194 & 66 & $34^{*}$ \\
\hline Non Diseased & 199 & 34 & $14^{*}$ \\
\hline Total & 393 & 100 & 25.4 \\
\hline
\end{tabular}

*Means a significant variation at $(\mathrm{P} \leq 0.05)$

This result give to Pasteurella multocida an important cause of respiratory diseases as a primary pathogens or it may be play a secondary role in the pathogenesis of various diseases $\left(^{4}\right)$.

Therefore, there are many studies were give same results on cattle and buffaloes as, $\left({ }^{14}\right)$ in Iran. which reported that more than $95 \%$ of buffaloes and $40 \%$ of the total number of cows were died because of Pasteurella multocida , and $\left({ }^{8}\right)$ in marshes in south of Iraq who recorded and isolated the causative agent of outbreak of HS in buffaloes during 2008. While $\left(^{7}\right)$ recorded distribution of (HS) in Sargodha division, Punjab province were isolated from healthy carrier (2\%) and diseased buffaloes (4\%).Also $\left(^{3}\right)$ in Baghdad revealed (38.88\%) isolations of Pasteurella multocida which were $(60 \%)$ from cows and $(30.76 \%)$ from buffalo.

\section{- Clinical signs}

The clinical signs of affected buffaloes with Pasteurellosis were .Anorexia, elevated body temperature, pneumonia resulting associated with coughing and rapid breathing, depression and restlessness. respiratory distress with nasal discharge, and frothing from the mouth with throat edema in some cases

Inspiratory dyspnea was seen, subsequent to respiratory distress, due to upper respiratory tract obstruction following throat edema. Death of affected animals may be seen or occur due to asphyxia, Other than the release of pharmacologically active substances, there is another school of thought in the development and consequences of HS that the Pasteurella multocida produces endotoxins which are responsible for all manifestations $\left({ }^{15}\right)$. Death of the animals occurs due to hypoxia and toxemia $\left({ }^{16}\right)$.

pneumonic pasteurellosis or BRD is caused by more than one species of Pasteurella and serotype. On the other hand Pasteurella play a secondary act in disease process, and more than one of viruses have been convicted with BRD. The disease is different syndromes that caused under different conditions, but Pasteurella have important role (primary or secondary) to cause (BRD) complex. $\left({ }^{4}\right)$ Such clinical findings of hemorrhagic septicemia were recorded by many authors such as $\left({ }^{17}\right)$. In West Bengal, and $\left({ }^{18}\right)$

\section{- The colony Pasteurella multocida on blood agar appeared as two forms}

First colonies were roughly and small discrete tear shaped colonies. When the another colonies were mucoid and large colonies. also no haemolysis on the blood agar , and No growth on MacConKey agar

Staining by Gram stain appeared as Gram negative, coccobacilli or short-rod singly or in pairs 
The identification of Pasteurella multocida isolates was done according to biochemical tests of ( oxidase +ve), $($ catalase $+v e)$, (indol +ve) where (urea -ve) and (Triple sugar iron result)

Tab. (4)Showed the Biochemical tests and its results for $P$. multocida

\begin{tabular}{|l|l|l|}
\hline No & Biochemical test & Result \\
\hline 1 & Urea test & -ve \\
\hline $\mathbf{2}$ & TSI Agar & slant color (yellow) bottom (yellow) gas (-ve) H2S (-ve) \\
\hline 3 & Indole test & +ve \\
\hline 4 & Oxidase test & + ve \\
\hline 5 & Catalase test & + ve \\
\hline
\end{tabular}

These findings were agreement with more than one authors like $\left({ }^{8,3}\right)$ whom found same characters to $P$. multocida

- Polymerase chain reaction assay.

All positive isolation were confirmed as P.multocida by the PCR method and they all match with speciesspecific 460 bp with the KMT1T7 and KMT1SP6 primers. In PCR assay, amplification was observed from all the isolates, applied to confirm the serotypes of P.multocida. This primers discovering by $\left({ }^{12}\right)$

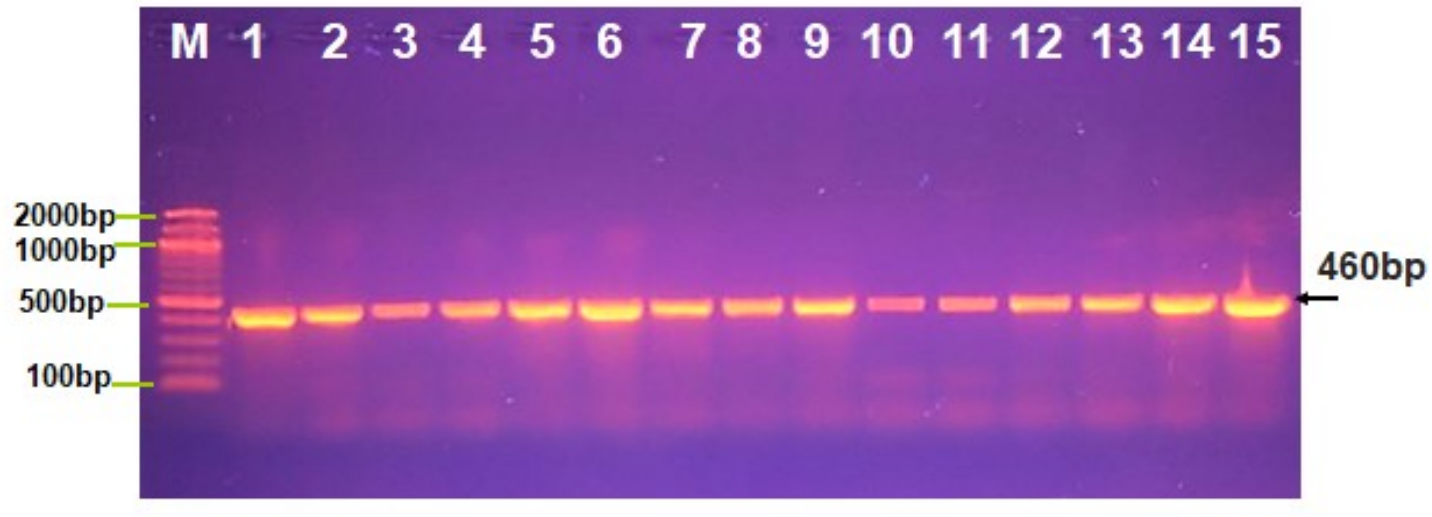

Figure (2): Agarose gel electrophoresis image that showed the PCR product analysis of diagnostic gene in Pasteurella multocida isolates. Where M: marker (2000-100bp), lane (1-15) positive isolates at (460bp) PCR product size.

These findings confirmed the results obtained by $\left({ }^{10,19.20}\right)$, whom reported approximately 460 bp amplified product from all P.multocida isolates.

- The distribution according_to sex . 
As well as the infection recorded in male $26 \%$ were higher but non-significant higher than female $25 \%$,Tab. (5);

Tab. (5) distribution of Pasteurella multocida in buffaloes according to sex

\begin{tabular}{|l|l|l|l|}
\hline sex & Sample & Positive & Distribution \% \\
\hline Female & 202 & 51 & 25 \\
\hline Male & 191 & 49 & 26 \\
\hline Total & 393 & 100 & 25.4 \\
\hline
\end{tabular}

This result is in agreement with.$\left(^{9}\right)$ and disagreed with $\left({ }^{10}\right)$ who recorded the percentage of female cases was higher than in male and may be due to that stress factors like pregnancy, milking and calving occurred in female

\section{- The distribution according_to age}

The number of infected buffaloes under one year of age(27.1\%) was significant higher than 1-2 year (16.1\%) and adult animal(16.1\%) at $(\mathrm{P} \leq 0.05)$ Tab. (6);

Tab. (6) distribution of Pasteurella multocida in buffaloes according to Age

\begin{tabular}{|l|l|l|l|}
\hline Age (year) & Sample & positive & Distribution(\%) \\
\hline Under 1 & 180 & 59 & $32.8 \%$ \\
\hline $1-2$ & 102 & 20 & $19.6 \%$ \\
\hline Above 2 & 111 & 21 & $18.9 \%$ \\
\hline Total & 393 & 100 & $25.4 \%$ \\
\hline
\end{tabular}

*Means a significant variation at $(\mathrm{P} \leq 0.05)$

Radostits et al ., (2007) $\left({ }^{21}\right)$. mentioned that all age groups are susceptible to infection, but in endemic regions, older animals previously exposed to the pathogen may have antibodies providing some protection. In these regions the most susceptible age group is 6 months to 2 years of age. Colostral immunity of calves from cows vaccinated against hemorrhagic septicemia peaks at 8 to 16 weeks of age and then declines, also there is no difference in susceptibility between breeds

This result is in agreement with $\left(^{22,23}\right)$ 


\section{- The distribution according to Provinces}

The Distribution rate were $25.3 \%, 24.4 \%, 26.4 \%$ in Basrah. Dhi Qar, Misan respectively but there were no significant variation between Provinces.

Tab. (7) distribution of Pasteurella multocida in buffaloes according to Provinces

\begin{tabular}{|l|l|l|l|}
\hline Provinces & Samples & Positive & Distribution \% \\
\hline Basrah & 130 & 33 & 25,3 \\
\hline Dhi Qar & 127 & 31 & 24.4 \\
\hline Misan & 136 & 36 & 26.4 \\
\hline Total & 393 & 100 & 25.4 \\
\hline
\end{tabular}

The Mesopotamian marshes, consist of three large marsh complexes: Al-Hawizeh, Central, and Al-Hammar in southern Iraq $\left(29^{\circ} 55^{\prime} 00^{\prime} \mathrm{N}\right.$ to $32^{\circ} 45^{\prime} 00^{\prime} \mathrm{N}$ and $45^{\circ} 25^{\prime} 00^{\prime} \mathrm{E}$ to $\left.48^{\circ} 30^{\prime} 00^{\prime} \mathrm{E}\right)$ are the biggest wetlands in Iraq and one of most important natural aquatic systems in region of Middle East ,also , one of the largest centers of buffaloes concentration in Iraq, up to $60 \%$ of buffaloes herd. Water supply to the marshes has fluctuated with the discharge of the Tigris and the Euphrates Rivers through the centuries and with the ability of Iraqi rulers to control water distribution, given the area's unique geology and seasonality.$\left({ }^{24}\right)$.

So these marshes have same environment therefore there were no significant variation between provinces.

\section{- Result of distribution according_to time}

The distribution of Pasteurella multocida infection, in clinical cases, through the months of the study, reported the highest number of infection during February /2018 (37\%), and decline in October $/ 2017(9 \%)$ Tab. (8);

Tab. (8) distribution of Pasteurella multocida in buffaloes according to month

\begin{tabular}{|l|l|l|l|l|l|}
\hline Year & Month & Location & samples & positive & Distribution \% \\
\hline
\end{tabular}




\begin{tabular}{|c|c|c|c|c|c|}
\hline \multirow{8}{*}{2017} & May/ & AlAmni & 20 & 7 & $33 \%$ \\
\hline & June & Alhower & 24 & 7 & $29 \%$ \\
\hline & July & AlMdina & 34 & 8 & $24 \%$ \\
\hline & August & Um Al Wadea & 38 & 9 & $24 \%$ \\
\hline & September & Al Musharah & 32 & 7 & $22 \%$ \\
\hline & October & Al Tar & 34 & 3 & $9 \% *$ \\
\hline & November & Al Misbaneah & 36 & 5 & $14 \%$ \\
\hline & December & Ghabishia & 35 & 7 & $20 \%$ \\
\hline \multirow{5}{*}{2018} & January & Showarea & 37 & 11 & $30 \%$ \\
\hline & February & Al Salam & 35 & 13 & $37 \% *$ \\
\hline & March & Ghibash & 35 & 12 & $34 \%$ \\
\hline & April & Al Adil & 33 & 11 & $33 \%$ \\
\hline & Total & & 393 & 100 & $25.4 \%$ \\
\hline
\end{tabular}

*Means a significant variation at $(\mathrm{P} \leq 0.05)$

\section{- Correlations between Distribution rates and environmental changes}

There were significant correlations between distribution rates and Mean of temperatures significant at the 0.01 level (2-tailed). But its non-significant Correlations between Distribution rates and Mean of Temperatures \& Humidity at Tab. (9). Tab. (10)

Tab. (9) Showed Correlations between Monthly distribution of Pasteurella multocida and environmental changes

\begin{tabular}{|c|c|c|c|c|}
\hline Year & Month & $\begin{array}{c}\text { Distribution rates } \\
\text { \% }\end{array}$ & $\begin{array}{c}\text { Mean of } \\
\text { Temperatures }\end{array}$ & Mean of Humidity \\
\hline 2017 & May/ & 33 & 32.3 & 27 \\
\hline
\end{tabular}


ISSN Onlin:2708-9347, ISSN Print: 2708-9339 Volume 9, Issue 1 (2020) PP 63-75

\begin{tabular}{|c|c|c|c|c|}
\hline & June & 29 & 36.6 & 16 \\
\hline & July & 24 & 39.2 & 18 \\
\hline & August & 24 & 39.7 & 22 \\
\hline & September & 22 & 34 & 24 \\
\hline & October & 9 & 30 & 29 \\
\hline & November & 14 & 20 & 38 \\
\hline & December & 20 & 15.2 & 42 \\
\hline \multirow{4}{*}{2018} & January & 30 & 12.5 & 63 \\
\hline & February & 37 & 14.4 & 55 \\
\hline & March & 34 & 19.5 & 37 \\
\hline & April & 33 & 25.8 & 32 \\
\hline
\end{tabular}

Tab. (10)Correlations between Distribution, Temperatures \& Humidity

\begin{tabular}{|l|l|l|l|l|}
\hline & Correlation & Distribution & Temperatures & Humidity \\
\hline Distribution & Pearson Correlation & 1 & $-.931-^{* *}$ & .251 \\
\hline Temperatures & Pearson Correlation & $-.931-^{* *}$ & 1 & $-.186-$ \\
\hline Humidity & Pearson Correlation & .251 & $-.186-$ & 1 \\
\hline
\end{tabular}

**Means a significant variation at $(\mathrm{P} \leq 0.01)$

Although clinical disease can occur at any time of the year, close herding and wet conditions clearly contribute to the spread of the disease. Outbreaks of the disease are often associated with wet, humid weather during the rainy season. Stressors such as inadequate feed supply or exhaustion are considered important predisposing factors that not only increase the susceptibility to clinical disease, but also stimulate shedding of the bacterium from subclinically infected animals.$\left(^{4,11}\right)$ 
Iraq one of countries outside tropical region, there for the rainy season in winter only . so there are correlations between distribution rates and mean of temperatures.

This result agreement with $\left({ }^{10}\right)$ and $\left({ }^{25}\right)$, but these finding was disagreement with the studies of India HS occur most commonly in the month of June- September (rainy season). The organism (Pasteurella multocida) does not survive outside the animal to any significant degree so as to be a source of infection. Moist condition prolong its survival outside the animal making an outbreak more likely. Thus the disease tends to spread more during the wet season $\left({ }^{26}\right)$

\section{iv. REFERENCES}

1. Merza, Mohammed (2008) Adherence To and Invasion Of Mammalian Cell Lines By Pasteurella Multocida B:2. Master Thesis Of Science In The Faculty Of Biomedical And Life Sciences, University Of Glasgow

2. Chung EL, Abdullah FF, Ibrahim HH, Marza AD, Zamri-Saad M, Haron AW, Lila MA, Norsidin MJ (2015). Clinico-pathology, hematology and biochemistry responses in buffaloes towards Pasteurella multocida type B: 2 immunogenlypo polysaccharide via oral and intravenous routes of infection. Microb. Pathog. 91:141-154.2487-2492.

3. Ahmed ,W. A.; Al- Rubaei E. M. and Majeed, Sh. A. (2015) Prevalence of pasteurella spp. apparently healthy cattle and buffaloes herd in Baghdad governorate, Iraq. Al-Anbar J. Vet. Sci., .: 8.(1), 36-43.

4. Constable PD, Hinchcliff KW, Done SH, Grünberg W.( 2017): Veterinary Medicine: A Textbook Of The Diseases Of Cattle, Horses, Sheep, Pigs, And Goats, 11th ed. Elsevier Ltd Co St. Louis, Missouri; Pp 2042 -2050.

5. OIE(2012) Principals of veterinary vaccine production. In: Manual of standards for diagnostic tests andvaccines for Terrestrial Animals. Seventh Edition: ISBN 978-92-9044-878-5 Volume1: ISBN 978-92-9044-880-8 Haemorrhagic septicaemia,; Pp 732-740.

6. Quinn PJ, Markey BK, Leonard FC, Hartigan P, Fanning S, Fitzpatrick ES(2011): Veterinary Microbiology and Microbial Disease (2nd Edition), Wiley-Blackwell Publishing,; Pp. 300-309.

7. Kamran ,M., M. Ahmad D., A. A. AnjumA. Maqbool, K. Muhammad, H. M. Khan, Hudda N., Nawaz ,M. and Ali, M. A.(2014) Antigenic Variation Among Pasteurella Multocida isolates 
From Diseased Buffaloes By Protein Profiling andCluster Analysis. Journal of Animal and Plant Sciences, 24(4):, Pp 1101-1109

8. Gadi JA, Al Amer KG, Abdullah MS.(2010) Diagnosis of H.S. in buffalos in marshes of south of Iraq in 2008. Al-Qadisiyah Journal of Veterinary Science,; 9(2):62-68.

9. Al-Hamed TA.(2010) Study of pasteurellosis in buffalo in Basrah. MSc Thesis. College of Veterinary MedicineUniversity of Basrah, Iraq.

10. Al-Shemmari I.(2013) Isolation And Molecular Identification Of P. Multocida From Cows And Buffaloes By Using Multiplex PCR Technique In Baghdad Province. Ph D. Thesis. Dept Of Internal And Preventive Medicine. College Of Veterinary Medicine. University Of Baghdad;.

11. Ahmed ,Waffa. A .; Nagham. M Al-Gburi; Hamoudi. S. Rassol . (2014). An Outbreak Of Hemorrhagic Septicemia In A Vaccinated Herd Of Domestic Water Buffalo In Thi Qar Province, Iraq: Clinical And Pathological Observations. MRVSA. 3 (2), 36-43.

12. Townsend, K.M., Frost.A.J., Lee.C.W., Papadimitriou.J.M., and Dawkins.H.J.S., (1998): Development Of PCR Assays For Species and Type Specific Identification of P. Multocida Isolates Journal Of Clinical Microbiology, 36:1096-1100.

13. Al-Rawi, Kh. M. (2000) . Introduction To A Statistical .Dar Al- Kutob For Distribution and Press . 2nd Ed, University Of Mosul , Mosul- Iraq

14. Mohammadi, GH.R, Ghazvini, k., Abbaspanah, H.(2003). Isolation and Identification of Pasterella Spp.in the Upper respiratory Tract of Healthy and Unhealthy Holstein (dairy calf pneumonia) calves, Journal of the Faculty of Veterinary Medicine University of Tehran 61, 2:147-153.

15. Horadagoda, N. U.; J. C. Hodgson, G. M.; Moon, T. G. Wijewardana And P. D. Eckersall (2001): Role Of Endotoxin In The Pathogenesis of haemorrhagic Septicaemia In The Buffalo. Microb. Pathog., 30:171-178.

16. Khin, M.N.; Zamri-Saad, M. And Noordin M.M. (2010): Pathological Changes In The Lungs Of Calves Following Intratracheal Exposure To Pasteurella Multocida B:2. Pertanika J Trop Agric Sci, 33: 113-117. 
17. Mitra .Joyjit *, Mintu Chowdhury And Chayan Bhattacharya (2013)Outbreak Of Hemorrhagic Septicemia In Free Range Buffalo And Cattle Grazing At Riverside Grassland In Murshidabad District, West Bengal, India .Explor. Anim. Med. Res., .3, ( 2), P. 178-182

18. Rajagopal, R ;Nair, G.K. and Mini, M. (2010) Pasteurellosis In A Buffalo Herd - A Brief Report ,Jiva Vol . 8 Issue 2 Pp:57-59

19. Townsend, K.M., Boyce, J.D., Chung, J.Y., Frost, A.J. and Alder, B. (2001): Genetic Organization Of Pasteurella Multocida Cap Loci and Development Of Multiplex Capsular PCR Typing System. Journal Clinical Microbiology 39 : 924-929.

20. Shayegh ,J; Sina A; , Taghi Z; and Mohammad S. H.(2010) Potential Of Pasteurella Multocida Isolated From Healthy and Diseased Cattle and Buffaloes In Induction Of Diseases Bull Vet Inst Pulawy 54, 299-304,

21. Radostits OM, Gay CC, Hinchcliff KW, Constable PD.( 2007) Veterinary Medicine: A Textbook of diseases of cattle, horses, sheep, pigs and goats. 10th ed, WB Saunders Co, Philadelphia, USA.; Pp. 921- 923.

22. Horadagoda, N. U., Hodgson, J. C., Moon, G. M., Wijewardana, T. G. And Eckersall, P. D. (2002). Development Of A Clinical Syndrome Resembling Haemorrhagic Septicaemia In The Buffalo Following Intravenous Inoculation Of Pasteurella Multocida Serotype B:2 Endotoxin And The Role Of Tumour Necrosis Factor-Alpha. Research In Veterinary Science 72, 194-200.

23. Khan A, Saddique U, Ahmad R, Khani H, Mohammad Y. and Zubair M, (2006). Serosurveillance Of Hemorrhagic Septicemia In Cattle and Buffaloes In District Malak And , NWFP. J. Anim. Vet. Adv. 5: 912-915.

24. Almaarofi 'Sama Sameer (2015) Ecological Assessment Of Re-Flooded Mesopotamian Marshes (Iraq) Ph.D. Thesis Presented To The University Of Waterloo

25. Verma, S.C.; Mahajan, N.K.; Malik, G. And Dahiya, J.P. (2004): An Epidemiological Study On Bovine Haemorrhagic Septicaemia In Haryana. Indian J.Anim.Res. 38:14-19.

26. Gajendragad M R, Uma $S$ and Rahaman H.(2012).Status Of HS In India. PD-ADMAS Techniscal Bull. 2011-2012. ICAR. Hebbal. Bengaluru. India. 